\title{
Tuning ultrafine manganese oxide nanowire synthesis seeded by Si particles and its superior Li storage behaviors
}

\author{
Hang Wei, Jin Ma, Biao Li, Li An, Junli Kong, Pingrong Yu and Dingguo Xia
}

The nanostructure and the dimension of materials greatly affect their performance and function. It is important to develop synthesis strategies that enable the control of the materials' morphology and structure and further reduce their size. In the present work, we report a novel synthesis approach that utilizes Si nanoparticles for synthesizing ultrafine MnO nanowires. The resulting nanostructure comprises $\mathrm{MnO}$ nanowires with a diameter of $\sim 5-10 \mathrm{~nm}$ embedded in an amorphous carbon matrix. $\mathrm{X}$-ray diffraction patterns and high-resolution transmission electron microscopy images clearly reveal the growth mechanism of nanowires. As an anode material for the lithium-ion battery, the nanostructure exhibits excellent charge transfer kinetics and extremely high electrochemical performance, including reversible specific capacities of $285.9 \mathrm{~mA} \mathrm{~h} \mathrm{~g}^{-1}$ at $30 \mathrm{~A} \mathrm{~g}^{-1}$ and $757.4 \mathrm{~mA} \mathrm{~h} \mathrm{~g}^{-1}$ at $1 \mathrm{~A} \mathrm{~g}^{-1}$ after 1000 cycles. X-ray absorption fine structure (XAFS) confirms that the enhanced performance is related to the increase of the ordering of the $\mathrm{O}^{2-}$ ions in the $\mathrm{MnO}$ structure during the charge/discharge processes. This novel synthesis strategy may inspire studies of other transition-metal-oxide nanomaterials with special orientation to tune their physical chemistry properties.

NPG Asia Materials (2016) 8, e255; doi:10.1038/am.2016.29; published online 25 March 2016

\section{INTRODUCTION}

One-dimensional (1D) nanostructures with a high surface-to-volume ratio and potential for quantum confinement have attracted the attention of materials scientists in recent years. ${ }^{1-4} \mathrm{MnO}$ is among the well-known technologically important materials used in diverse application areas, including in electronics, ${ }^{5}$ sensors, ${ }^{6}$ magnetic storage media, ${ }^{7}$ optical ${ }^{8}$ and catalysis, ${ }^{9}$ especially lithium-ion batteries. ${ }^{10-18}$ Several techniques for the synthesis of $\mathrm{MnO} 1 \mathrm{D}$ structures have been made available. Guo and co-workers ${ }^{11}$ designed an $\mathrm{MnO} /$ carbon nanopeapod nanostructure with an internal void space by annealing the $\mathrm{MnO}$ precursor/polydopamine core/shell nanostructure. This anode material exhibits a high reversible capacity. Huang and co-workers ${ }^{12}$ proposed $\mathrm{N}$-doped carbon webs to support $\mathrm{MnO}$ nanoparticles, which also exhibit great electrochemical performance. It has been demonstrated that decreasing the size of $\mathrm{MnO}$ particles to the nanoscale can mitigate the physical strains during the $\mathrm{Li}$ uptake/release process, so that the volume change causes less cracking and particle pulverization. However, to the best of our knowledge, there are fewer reports about the controllable synthesis of ultrafine $\mathrm{MnO}$ nanowire-seeded particles. Since the performance and function of nanowires can be deliberately tuned through size- and shape-dependent effects, the development of reliable and controlled syntheses for 1D nanostructures is necessary.
Herein, we report a novel approach that utilizes Si nanoparticles for synthesizing ultrafine $\mathrm{MnO}$ nanowires with $\sim 5-10 \mathrm{~nm}$ in diameter. $\mathrm{X}$-ray diffraction (XRD) patterns and high-resolution transmission electron microscopy (HRTEM) images clearly reveal the growth mechanism of $\mathrm{MnO}$ nanowires. As an anode material for the lithium-ion battery, the $\mathrm{MnO}$ nanowires exhibit an excellent charge transfer kinetics performance. This synthesis strategy may inspire studies of other TMO nanomaterials with special orientation to tune their physical chemistry properties.

\section{MATERIALS AND METHODS}

Synthesis of $\mathrm{MnCO}_{3}$ nanowires

The Beijing Chemical Reagent Center supplied $\mathrm{KMnO}_{4}$, glycol, phthalocyanine (Pc), sodium dodecyl sulfate, pyrazine, $\mathrm{N}, \mathrm{N}$-dimethyl formamide and other chemical reagents of analytical grade, which were used as received. The $\mathrm{MnCO}_{3}$ precursor was prepared by a hydrothermal method. ${ }^{19}$ First, $0.7 \mathrm{~g}$ of $\mathrm{KMnO}_{4}$ powder was dissolved into a $40 \mathrm{ml}$ glycol solution (glycol: $\mathrm{H}_{2} \mathrm{O}=1: 3(\mathrm{v} / \mathrm{v})$ ) to form a purple solution. Different amounts of Si nanoparticles were mixed with the glycol solution and annealed inside a $50 \mathrm{ml}$ Teflon-lined autoclave at $180{ }^{\circ} \mathrm{C}$ for $24 \mathrm{~h}$. The molar ratio of $\mathrm{Si}$ and $\mathrm{KMnO}_{4}$ was adjusted from 0:1 to 1:2. The $\mathrm{MnCO}_{3}$ precursor was first collected by filtration after the reaction was completed. For the separation of the $\mathrm{Mn}_{7} \mathrm{SiO}_{12}$ nanoparticles and $\mathrm{MnCO}_{3}$ nanowire, a centrifugation process was performed. Firstly, the as-prepared sample was dispersed in the glycerol solution (glycerol: $\mathrm{H}_{2} \mathrm{O}=1: 1(\mathrm{v} / \mathrm{v})$ ) by an ultrasonic method. Then, the bigger $\mathrm{Mn}_{7} \mathrm{SiO}_{12}$ nanoparticles were separated by

Key Lab of Theory and Technology for Advanced Batteries Materials, College of Engineering, Peking University, Beijing, People's Republic of China Correspondence: Professor D Xia, Key Lab of Theory and Technology for Advanced Batteries Materials, College of Engineering, Peking University, Beijing 100871, People's Republic of China.

E-mail: dgxia@pku.edu.cn

Received 26 May 2015; revised 14 November 2015; accepted 30 November 2015 
centrifugation at 5000 r.p.m. for $5 \mathrm{~min}$. Finally, the $\mathrm{MnCO}_{3}$ nanowire was obtained by vacuum filtration, purified thoroughly with distilled water and dried at $80^{\circ} \mathrm{C}$ in a vacuum oven.

\section{Synthesis of $\mathrm{MnO} @ \mathrm{C}$ nanowires}

In order to synthesize the $\mathrm{MnO} @ \mathrm{C}$ nanowires, $0.008 \mathrm{~mol}$ of $\mathrm{MnCO}_{3}, 0.001 \mathrm{~mol}$ of Pc, $0.001 \mathrm{~mol}$ of sodium dodecyl sulfate and $0.003 \mathrm{~mol}$ of pyrazine were added to $35 \mathrm{ml}$ of $\mathrm{N}, \mathrm{N}$-dimethyl formamide. A homogeneous solution was obtained after stirring and then transferred into a $50 \mathrm{ml}$ Teflon-lined autoclave that was heated in an electric oven at $160^{\circ} \mathrm{C}$ for $4.5 \mathrm{~h}$. The sample was collected by a vacuum rotary evaporation method and annealed in a tube furnace at $700{ }^{\circ} \mathrm{C}$ for $1 \mathrm{~h}$ in an $\mathrm{Ar}$ atmosphere. As a result, the MnO@C nanowires composite was obtained. For comparison, the pure $\mathrm{MnO}$ nanoparticles were prepared by annealing $\mathrm{MnCO}_{3}$ nanoparticles in a tube furnace at $700{ }^{\circ} \mathrm{C}$ for $1 \mathrm{~h}$ in an $\mathrm{H}_{2} / \mathrm{Ar}(5 \%)$ atmosphere.

\section{Characterization}

Powder XRD patterns were obtained using a Bruker D8 Advance diffractometer (Karlsruhe, Germany) with $\mathrm{Cu} \mathrm{K} \alpha$ irradiation $(\lambda=1.5406 \AA)$. X-ray photoelectron spectroscopy measurements were performed using an Axis Ultra system with monochromatic $\mathrm{Al} \mathrm{K \alpha} \mathrm{X}$-rays $(1486.6 \mathrm{eV})$. A thermogravimetric analysis was performed using a TG/DTA6300 thermal analyzer (Hiroshima, Japan) at a heating rate of $5{ }^{\circ} \mathrm{C} \mathrm{min}{ }^{-1}$ in a flowing-air atmosphere. The morphology and composition of the nanocomposite were measured by transmission electron microscopy (TEM; TECNAI-F20) and scanning transmission electron microscopy (STEM, FEI Titan G2 80- 200 Probe Cs-corrector, Hillsboro, OR, USA). Scanning electron microscopy was performed using a Hitachi S-4800. Ex situ Mn K-edge XAS (X-ray absorption spectroscopy) spectra were collected at the beamline 1W2B with an $\mathrm{Si}$ (111) double-crystal monochromator at the Beijing Synchrotron Radiation Facility. The sample was prepared after the charge/ discharge processes at a current density of $1 \mathrm{Ag}^{-1}$. Then, the cell was disassembled in the argon-filled glove box, and the sample was removed. In all the test procedures, the sample was sealed in $3 \mathrm{~m}$ tape and a plastic package. The XAS data were analyzed using standard IFEFFIT procedures.

\section{Electrochemical measurements}

2032-type coin cells were used for testing the LIBs with the MnO@C nanowires composite, that is, the working electrode comprising the MnO@C nanocomposite, acetylene black (Super P) and sodium alginate binder in the 70:20:10 weight ratio. The loading of active material on the current collector is $2-3 \mathrm{mg} \mathrm{cm}^{-2}$. When the mixed substance was dispersed in distilled water and the slurry was cast onto stainless-steel foils, the electrode was prepared. Besides, in order to carry on the XAS experiments, the working electrode was prepared by $\mathrm{MnO} @ \mathrm{C}$ nanocomposite, acetylene black (Super P) and PVDF in the same weight ratio slurry coated onto a copper foil substrate. The coin cells were assembled in a glove box in an Ar atmosphere, with lithium metal as the counter electrode. A glass fiber (GF/D) from Whatman was used as the separator, and $1 \mathrm{M} \mathrm{LiPF}_{6}$ in ethylene carbonate/dimethyl carbonate $(\mathrm{v} / \mathrm{v}=1: 1)$ was the electrolyte. Charge-discharge tests were performed on a Neware battery tester (Neware, Shenzhen, China) with a galvanostat for various current densities in the range of $0.2-30 \mathrm{~A} \mathrm{~g}^{-1}$ in the voltage range of $0.01-3 \mathrm{~V}$ at room temperature. The specific capacities are calculated based on the total mass of the MnO@C nanocomposite.

\section{RESULTS AND DISCUSSION}

\section{Synthesis and characterization of $\mathrm{MnCO}_{3}$ nanowire}

Supplementary Figure S1 shows a schematic of the mechanism that we propose to account for the progress of manganese oxide into the $1 \mathrm{D}$ nanowires. The $\mathrm{Mn} / \mathrm{Si}$ ratio is critical to this growth mechanism. $\mathrm{KMnO}_{4}$, a basic oxidizing agent and manganese precursor, can easily be reduced to $\mathrm{MnCO}_{3}$ nanoparticles by glycol under hydrothermal conditions, ${ }^{19}$ as indicated by Equation (1):

$$
2 \mathrm{MnO}_{4}{ }^{-1}+\mathrm{C}_{2} \mathrm{H}_{6} \mathrm{O}_{2} \rightarrow 2 \mathrm{MnCO}_{3}+2 \mathrm{H}_{2} \mathrm{O}+2 \mathrm{OH}^{-}
$$

The XRD pattern in Supplementary Figure S2a also confirms the formation of $\mathrm{MnCO}_{3}$ (JCPDS no. 07-0230) ${ }^{19}$ with a small amount of $\mathrm{Mn}_{3} \mathrm{O}_{4}$ (JCPDS no. 24-0734). ${ }^{20} \mathrm{MnCO}_{3}$ nanoparticles feature spheres with a diameter less than $100 \mathrm{~nm}$, as shown in the TEM image in Supplementary Figure S2b. When Si nanoparticles were introduced, the powder XRD pattern indicated the presence of an $\mathrm{Mn}_{7} \mathrm{SiO}_{12}$ (JCPDS no. 41-1367) ${ }^{21}$ novel phase, as well as $\mathrm{MnCO}_{3}$ and a small amount of $\mathrm{Mn}_{3} \mathrm{O}_{4}$, as shown in Figure 1. With the increase in the amount of $\mathrm{Si}$, the characteristic peaks corresponding to $\mathrm{Mn}_{7} \mathrm{SiO}_{12}$ became more obvious. Based on the reactants and products, the reaction equation could be

$$
\begin{aligned}
& 14 \mathrm{MnO}_{4}{ }^{-1}+2 \mathrm{Si}+5 \mathrm{C}_{2} \mathrm{H}_{6} \mathrm{O}_{2} \rightarrow 2 \mathrm{Mn}_{7} \mathrm{SiO}_{12}+7 \mathrm{CO}_{3}{ }^{2-} \\
& +3 \mathrm{CO}_{2}+15 \mathrm{H}_{2} \mathrm{O}
\end{aligned}
$$

Equations (1) and (2) occur simultaneously. It is noteworthy that product $\mathrm{MnCO}_{3}$ can not only be formed separately but also could be generated on the surface of the $\mathrm{Mn}_{7} \mathrm{SiO}_{12}$ by lattice match. To figure out the mechanism of $\mathrm{MnCO}_{3}$ nanowire growth, the morphology of the products for different $\mathrm{Mn} / \mathrm{Si}$ molar ratios was characterized by TEM, as shown in Figure 2. It can be found that the $\mathrm{Mn} / \mathrm{Si}$ ratio is a crucial factor affecting the morphology of the as-obtained products. The pristine Si nanoparticles are sphere-like particles $\sim 100 \mathrm{~nm}$ in diameter (Supplementary Figure S3). When the $\mathrm{Mn} / \mathrm{Si}$ molar ratio is 16:1, no Si phase was observed, and the products comprise $\mathrm{MnCO}_{3}$ and $\mathrm{Mn}_{7} \mathrm{SiO}_{12}$. The amount of $\mathrm{Mn}_{7} \mathrm{SiO}_{12}$ is very small so that there

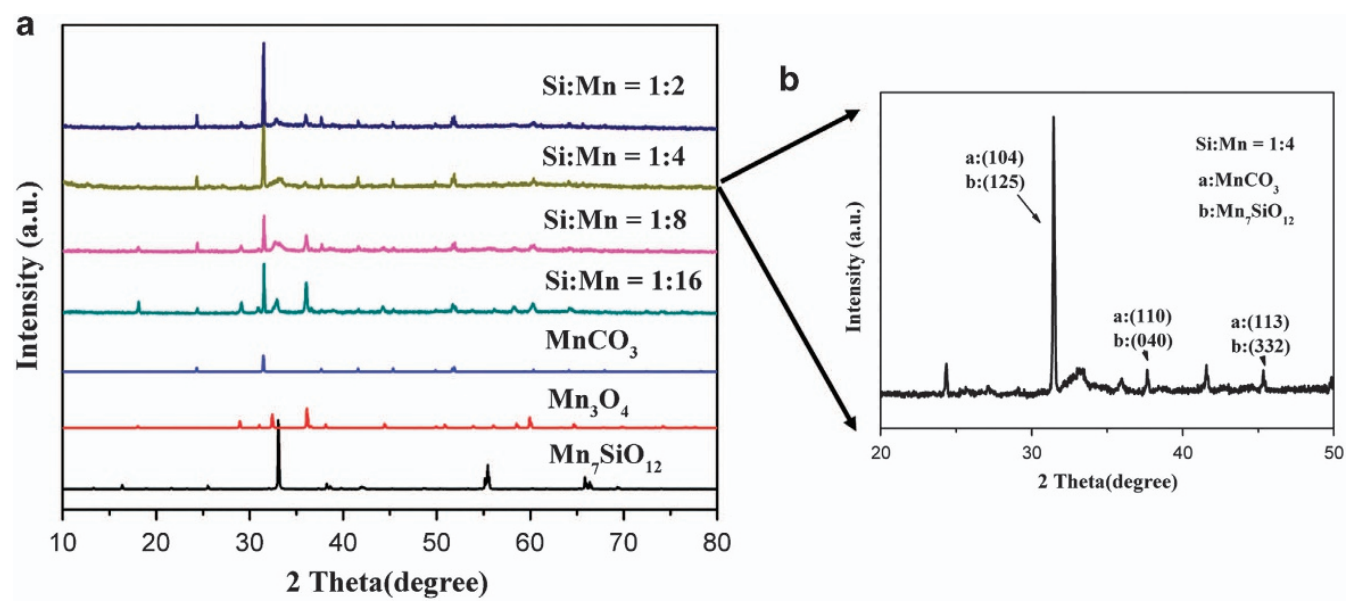

Figure $1 \mathrm{X}$-ray diffraction patterns of $\mathrm{MnCO}_{3}$ product obtained after hydrothermal reaction at $180{ }^{\circ} \mathrm{C}$ for $24 \mathrm{~h}$ for different molar ratios. 

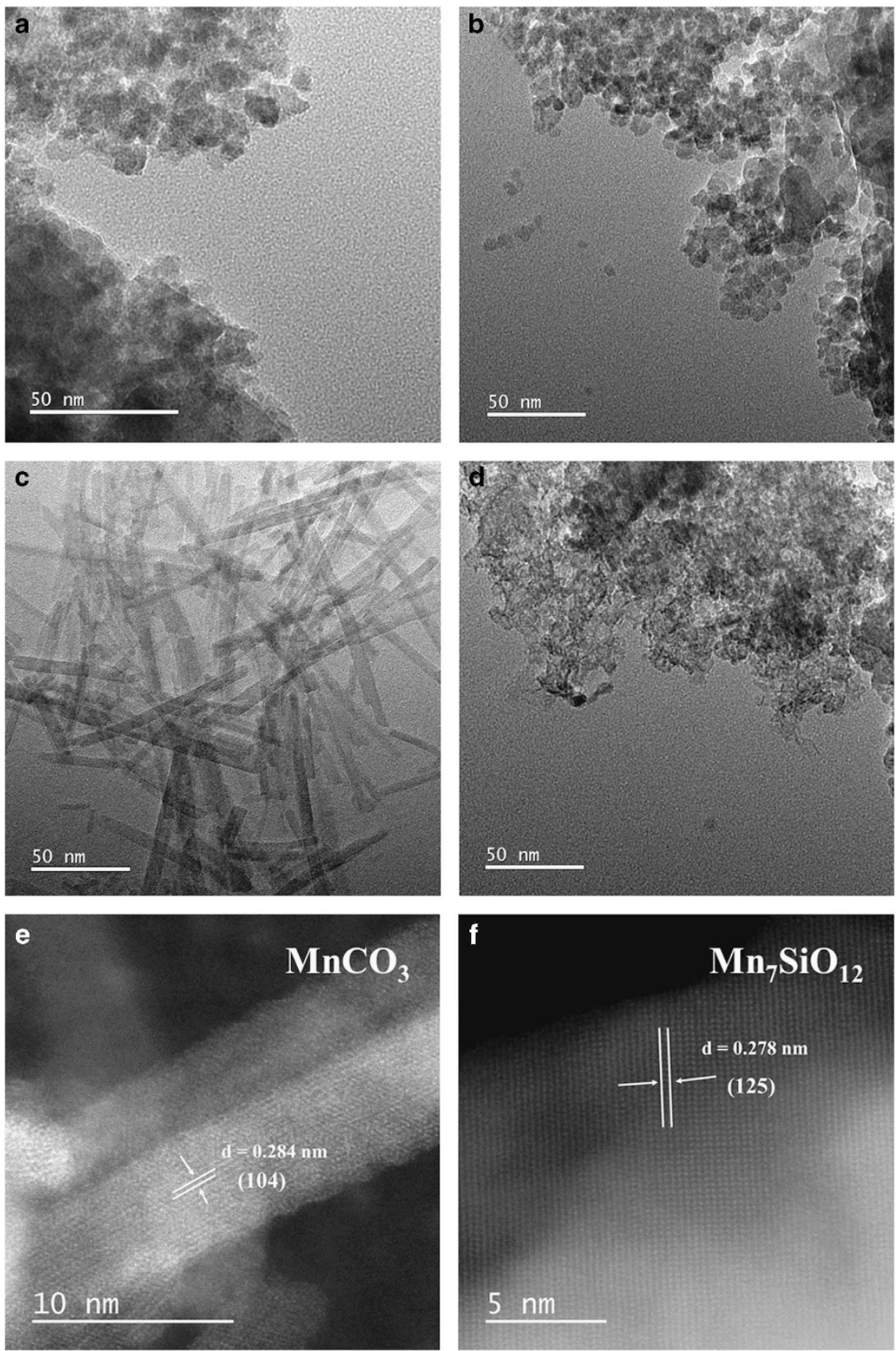

Figure 2 Transmission electron microscopy images of $\mathrm{MnCO}_{3}$ product obtained after hydrothermal reaction at $180{ }^{\circ} \mathrm{C}$ for $24 \mathrm{~h}$ in $\mathrm{Mn} / \mathrm{Si}$ molar ratios of (a) $16 / 1$, (b) $8 / 1$, (c) $4 / 1$ and (d) $2 / 1$. STEM images of (e) $\mathrm{MnCO}_{3}$ and (f) $\mathrm{Mn}_{7} \mathrm{SiO}_{12}$.

are not enough sites for the growth of $\mathrm{MnCO}_{3}$ nanowires on the surface of $\mathrm{Mn}_{7} \mathrm{SiO}_{12}$ by lattice match. That means $\mathrm{MnCO}_{3}$ particles are mainly formed alone. Therefore, the morphology of the as-obtained products features an agglomerate of nanoparticles that are several nanometers in diameter (Figure 2a). When the $\mathrm{Mn} / \mathrm{Si}$ molar ratio is $8: 1$ (Figure $2 \mathrm{~b}$ ), the phase composition and product morphology do not change, remaining as an agglomerate of sphere particles. When this ratio is changed to 4:1 (Figure 2c), the balance between the forming rate of $\mathrm{MnCO}_{3}$ and the amount of sites for the growth of $\mathrm{MnCO}_{3}$ on the surface of $\mathrm{Mn}_{7} \mathrm{SiO}_{12}$ may be suitable for the growth of $\mathrm{MnCO}_{3}$ nanowires by lattice match. As a result, ultrafine $\mathrm{MnCO}_{3}$ nanowires less than $10 \mathrm{~nm}$ in diameter are obtained.
The resultant $\mathrm{MnCO}_{3}$ nanowires disperse uniformly and are interconnected. Increasing the $\mathrm{Mn} / \mathrm{Si}$ molar ratio up to $2: 1$ (Figure 2d), there are so many sites for the growth of $\mathrm{MnCO}_{3}$ on the surface of $\mathrm{Mn}_{7} \mathrm{SiO}_{12}$ that the amount of $\mathrm{KMnO}_{4}$ may not meet for the continuous growth of nanowires. Therefore, $\mathrm{MnCO}_{3}$ demonstrates irregular morphology around the $\mathrm{Mn}_{7} \mathrm{SiO}_{12}$ particles.

Previous works reported that heterogeneous nanostructure materials can be synthesized by the epitaxial growth of different crystals. $^{22,23}$ If the lattice mismatches are sufficiently small, the epitaxial growth is tolerated and the heterogeneous $1 \mathrm{D}$ nanostructure can be formed. Based on the XRD data, the lattice mismatches (Supplementary Figure S4) between (104), (110), (113) planes of 


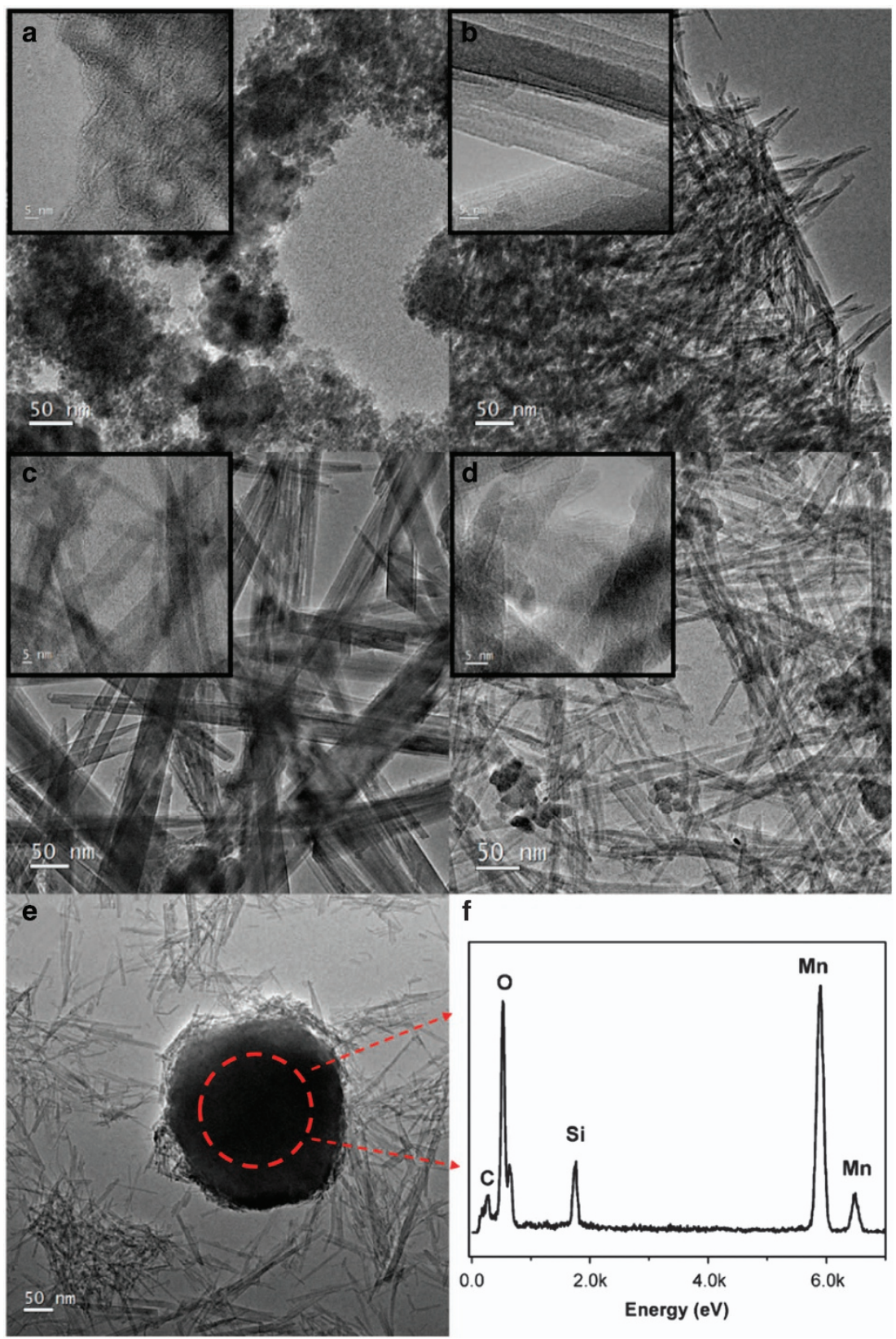

Figure 3 Transmission electron microscopy images of $\mathrm{MnCO}_{3}$ nanowire product obtained after hydrothermal reaction at $180{ }^{\circ} \mathrm{C}$ for different times (a) 4 , (b) 8, (c) 12, (d) 18 and (e) $24 \mathrm{~h}$. High-resolution transmission electron microscopy images are shown in the upper left corners. (f) Energy dispersive spectrometer (EDS) of marked area in e.

standard $\mathrm{MnCO}_{3}$ and (125), (040), (332) planes of standard $\mathrm{Mn}_{7} \mathrm{SiO}_{12}$ are almost $0 \%$. From Figures $2 \mathrm{e}$ and $\mathrm{f}$, the lattice planes of the $\mathrm{MnCO}_{3}$ nanowires are determined to be (104), while those of the $\mathrm{Mn}_{7} \mathrm{SiO}_{12}$ particles are assigned to be (125). The lattice match between the (104) planes of $\mathrm{MnCO}_{3}$ nanowires and the (125) planes of $\mathrm{Mn}_{7} \mathrm{SiO}_{12}$ particles is good. Consequently, $\mathrm{MnCO}_{3}$ can easily grow on the $\mathrm{Mn}_{7} \mathrm{SiO}_{12}$ nanomaterial to become $1 \mathrm{D}$ nanowires. Figure 3 compared the TEM images of the $\mathrm{MnCO}_{3}$ nanowires at different reaction times. $\mathrm{KMnO}_{4}$ first reacted with the Si nanoparticles to form small $\mathrm{Mn}_{7} \mathrm{SiO}_{12}$ particles with rough surfaces in the initial stage (Figure 3a). After the Si nanoparticles were consumed, the growth of $\mathrm{Mn}_{7} \mathrm{SiO}_{12}$ stopped, and $\mathrm{MnCO}_{3}$ nanowires gradually formed on the surface of the $\mathrm{Mn}_{7} \mathrm{SiO}_{12}$ owing to the lattice match and the appropriate $\mathrm{Mn} / \mathrm{Si}$ molar ratio (Figure $3 \mathrm{~b}$ ). It was found that the $\mathrm{MnCO}_{3}$ nanowire continued to grow longer and wider for $12 \mathrm{~h}$ after the reaction (Figure $3 \mathrm{c}$ ). When the hydrothermal reaction time was increased, the diameter of the $\mathrm{MnCO}_{3}$ nanowire started to shrink, which is attributed to the aging of the $\mathrm{Mn}_{7} \mathrm{SiO}_{12}$ (Figures $3 \mathrm{~d}$ and e). After a $24 \mathrm{~h}$ reaction, the presence of the $\mathrm{Mn}_{7} \mathrm{SiO}_{12}$ nanoparticles and $\mathrm{MnCO}_{3}$ nanowire was observed in the final product (Figure 3e). The $\mathrm{Mn}, \mathrm{Si}$ and $\mathrm{O}$ elements in the $\mathrm{Mn}_{7} \mathrm{SiO}_{12}$ particles were confirmed by energy-dispersive spectrometry (Figure $3 \mathrm{f}$ ). Because of the weight difference between the big $\mathrm{Mn}_{7} \mathrm{SiO}_{12}$ particles and $\mathrm{MnCO}_{3}$ nanowires, the $\mathrm{MnCO}_{3}$ nanowire can be easily separated by centrifugation, similar to the Evans'work. ${ }^{24}$ After separation, no obvious signal of Si element can be found from the energy-dispersive spectrometry result. 
a
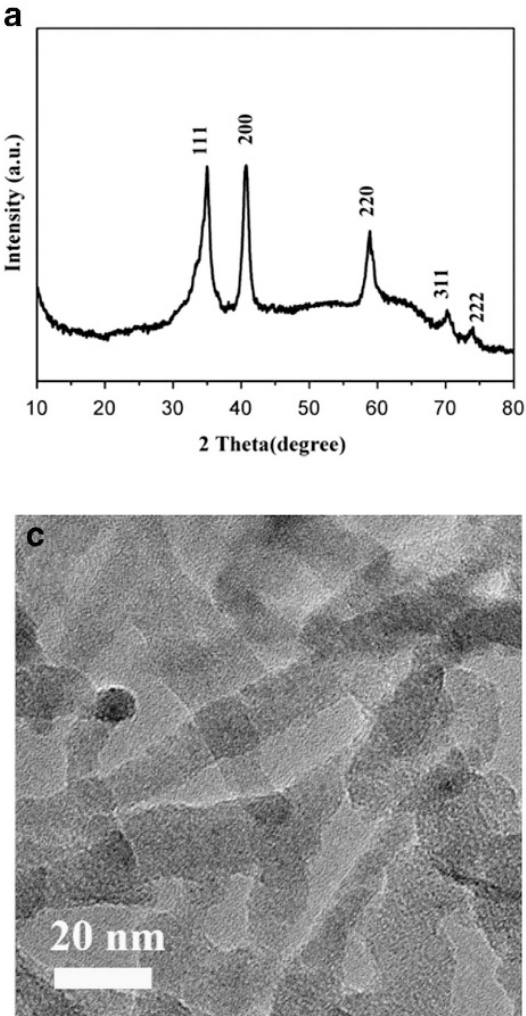
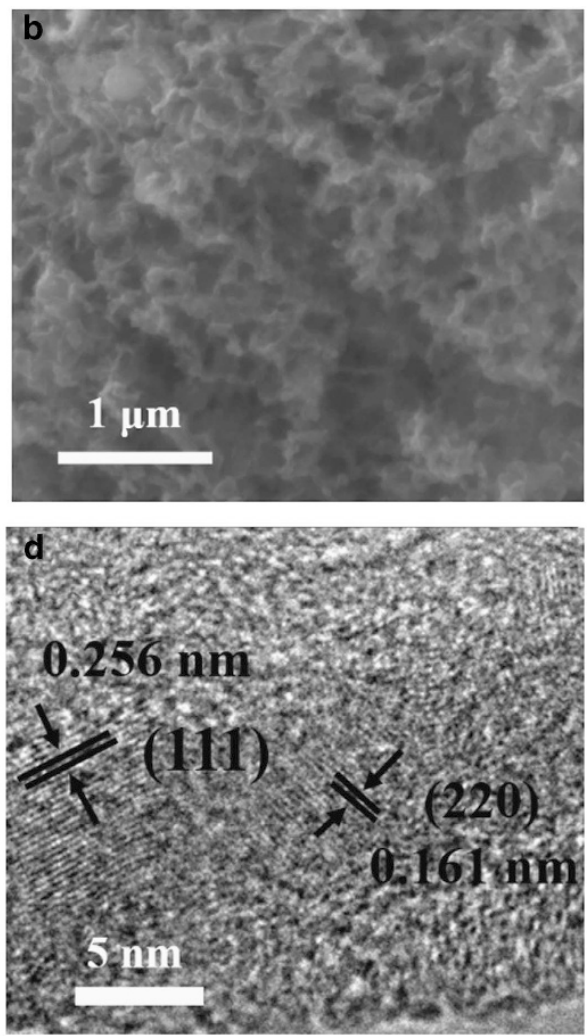

Figure 4 (a) X-ray diffraction pattern, (b) field emission scanning electron microscope, (c) Transmission electron microscopy and (d) High-resolution transmission electron microscopy images of as-synthesized MnO@C nanowire contained 25.1\% amorphous carbon.
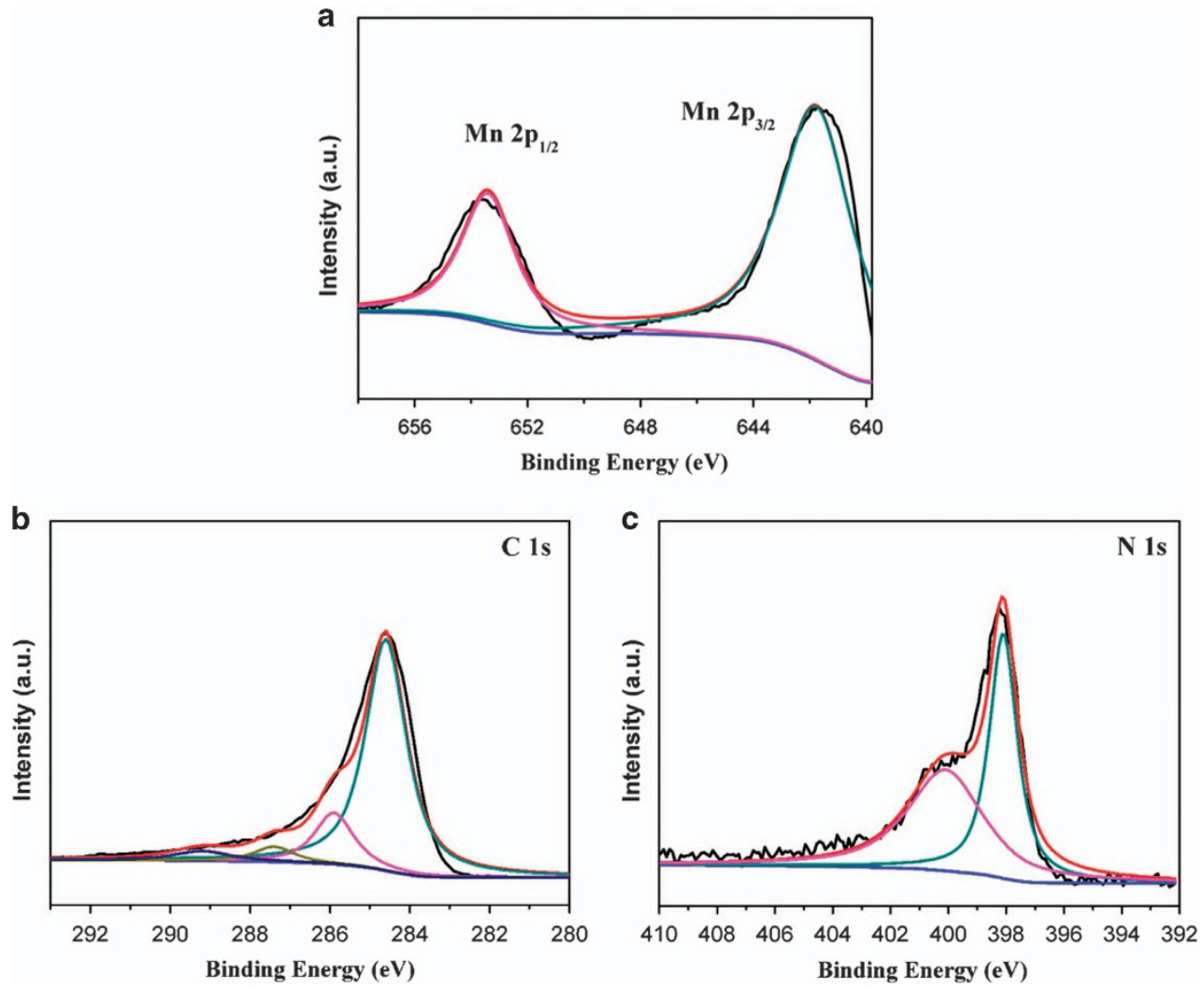

Figure 5 (a) Mn 2p, (b) C 1s, (c) N 1s X-ray photoelectron spectroscopy spectra of as-synthesized MnO@C nanowire. 

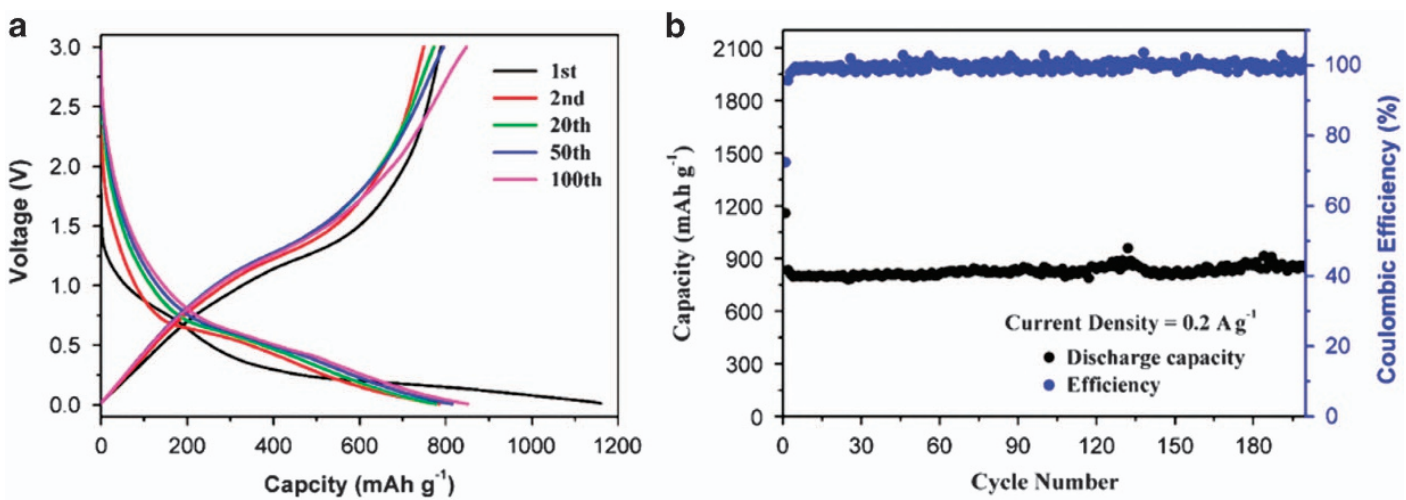

Figure 6 (a) Charge-discharge curves and (b) cycling performance and Coulombic efficiency of MnO@C electrodes at $0.2 \mathrm{~A} \mathrm{~g}^{-1}$ current density.

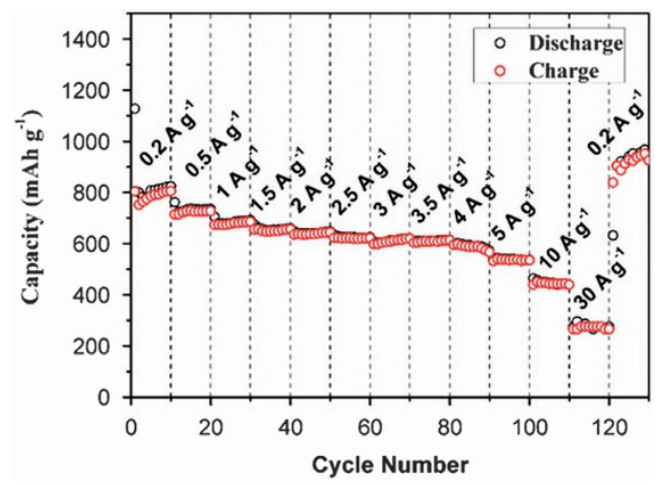

Figure 7 Charge and discharge profiles of $\mathrm{MnO@C} \mathrm{nanowires} \mathrm{at} \mathrm{different}$ current rates (from 0.2 to $30 \mathrm{Ag}^{-1}$ ).

Combined with the XRD results above, it can be concluded that the product is mainly composed of $\mathrm{MnCO}_{3}$ nanowires. According to our knowledge, this is the first report about the epitaxial growth of compounds.

\section{Synthesis and characterization of $\mathrm{MnO} @ \mathrm{C}$ nanowire}

The MnO@C nanowire composites were synthesized via polymerization-pyrolysis steps (see Materials and methods for more details). The typical XRD pattern of the MnO@C nanowires is presented in Figure $4 \mathrm{a}$. All the diffraction peaks could be readily assigned to a pure cubic phase of $\mathrm{MnO}$ (JCPDS no. 07-0230), ${ }^{25}$ and no other impurity phases are detected. Significantly, the broadening peaks indicate the ultrafine structure of the $\mathrm{MnO}$ nanowires, which inhibits its pulverization and facilitates the diffusion of lithium ions. ${ }^{11}$ The SEM and TEM images in Figures $4 \mathrm{~b}$ and $\mathrm{c}$ show that the as-prepared MnO@C composites are nanowire-like and have crossed connections with each other. The $\mathrm{MnO}$ nanowires are finely confined by the carbon framework, as shown in the HRTEM image of Figure 4d. This HRTEM image also reveals that crystalline $\mathrm{MnO}$ nanowires were embedded in the matrix of an amorphous carbon. The lattice fringes with interplanar distances of 0.266 and $0.161 \mathrm{~nm}$ can be assigned to the (111) and (220) planes of $\mathrm{MnO}$, respectively. The pyrolysis carbonaceous matrix acts as not only a volume buffer but also a conductive network when the composite of $\mathrm{MnO}$ and matrix is used as anode material in the LIBs during the charge-discharge process. ${ }^{10-12,25,26}$ Moreover, a thermogravimetry analysis was performed to further illustrate the carbon content of the composite (Supplementary Figure S5). The first weight loss was $\sim 1.4 \%$ and occurred below $200{ }^{\circ} \mathrm{C}$, which can be attributed to the desorption of absorbed water. The second weight loss of $\sim 12.1 \%$ occurred from 200 to $900{ }^{\circ} \mathrm{C}$ and was due to the integrative effect of the combustion of the $\mathrm{N}$-doping carbon and oxygenation of the $\mathrm{MnO}$ to $\mathrm{Mn}_{2} \mathrm{O}_{3} \cdot{ }^{10}$ Therefore, the amount of $\mathrm{MnO}$ and amorphous carbon in the MnO@C nanowire can be calculated as 74.9 and 25.1\%, respectively.

To further investigate the surface electronic state of the MnO@C composite, X-ray photoelectron spectroscopy measurements were performed. As shown in the Mn $2 \mathrm{p}$ spectrum (Figure $5 \mathrm{a}$ ), the two signals at 641.4 and $653.4 \mathrm{eV}$ are ascribed to $\mathrm{Mn} 2 \mathrm{p} 1 / 2$ and $\mathrm{Mn} 2 \mathrm{p} 3 / 2$, respectively, which can be attributed to the characteristics of $\mathrm{MnO} .^{27}$ Meanwhile, the C $1 \mathrm{~s}$ spectrum (Figure $5 \mathrm{~b}$ ) can be resolved into four peaks. The strong peak at $286.3 \mathrm{eV}$ corresponds to the $\mathrm{C}-\mathrm{C}$ bonds in the carbon matrix, and the small peaks at $285.8,287.5$ and $289.3 \mathrm{eV}$ reveal the existence of oxygen-carbon bonds from the insufficient carbonization process. ${ }^{27}$ The two peaks at 398.2 and $400.2 \mathrm{eV}$ can be resolved from the peaks of the $\mathrm{N} 1 \mathrm{~s}$ spectrum (Figure $5 \mathrm{c}$ ), which can be ascribed to graphene nitrogen and conjugated nitrogen, respectively. ${ }^{26,27}$ Graphene nitrogen, a pyridine-type nitrogen, enhances the electrochemical performance of anode materials. ${ }^{28,29}$ The aforementioned findings indicate the outstanding electrochemical performance of the MnO@C composite as an anode material for LIBs.

\section{Electrochemical properties of $\mathrm{MnO} @ \mathrm{C}$ nanowire}

The electrochemical lithium-storage properties of the as-prepared $\mathrm{MnO} @ \mathrm{C}$ nanocomposite were further investigated. As shown in Figure $6 \mathrm{a}$, two distinct long voltage plateaus are clearly observed around 0.5 and $1.2 \mathrm{~V}$ during the discharge-charge process, which agrees well with the cyclic voltammogram analysis (Supplementary Figure S6). Figure $6 \mathrm{~b}$ demonstrates the cycling performance and Coulombic efficiency of the $\mathrm{MnO} @ \mathrm{C}$ electrodes at a current density of $0.2 \mathrm{Ag}^{-1}$. The initial discharge and charge specific capacities are 1158.7 and $853.8 \mathrm{~mA} \mathrm{~h} \mathrm{~g}^{-1}$, respectively, based on the total mass of the MnO@C nanocomposite. The large initial discharge capacity of the MnO@C electrode could be attributed to irreversible Li insertion into the nanocomposites, in addition to the formation of SEI films on the surface of the electrode materials. After 200 cycles, the discharge capacity still retains $862 \mathrm{~mA} \mathrm{~h} \mathrm{~g}^{-1}$ with Coulombic efficiencies near $100 \%$, indicating a high accessibility for the lithium insertion and extraction. The TEM images in Supplementary Figure S7 show that the cross-linked structure of the MnO@C nanocomposite is completely retained after 80 discharge/charge cycles.

Figure 7 shows the charge and discharge profiles of a sample obtained at different current densities and indicates that $\mathrm{MnO} @ \mathrm{C}$ nanowires can be ultra-rapidly charged and discharged. The specific discharge capacities are $704.9,646.4,620.5,601.8$ and $543.8 \mathrm{~mA} \mathrm{~h} \mathrm{~g}^{-1}$ 

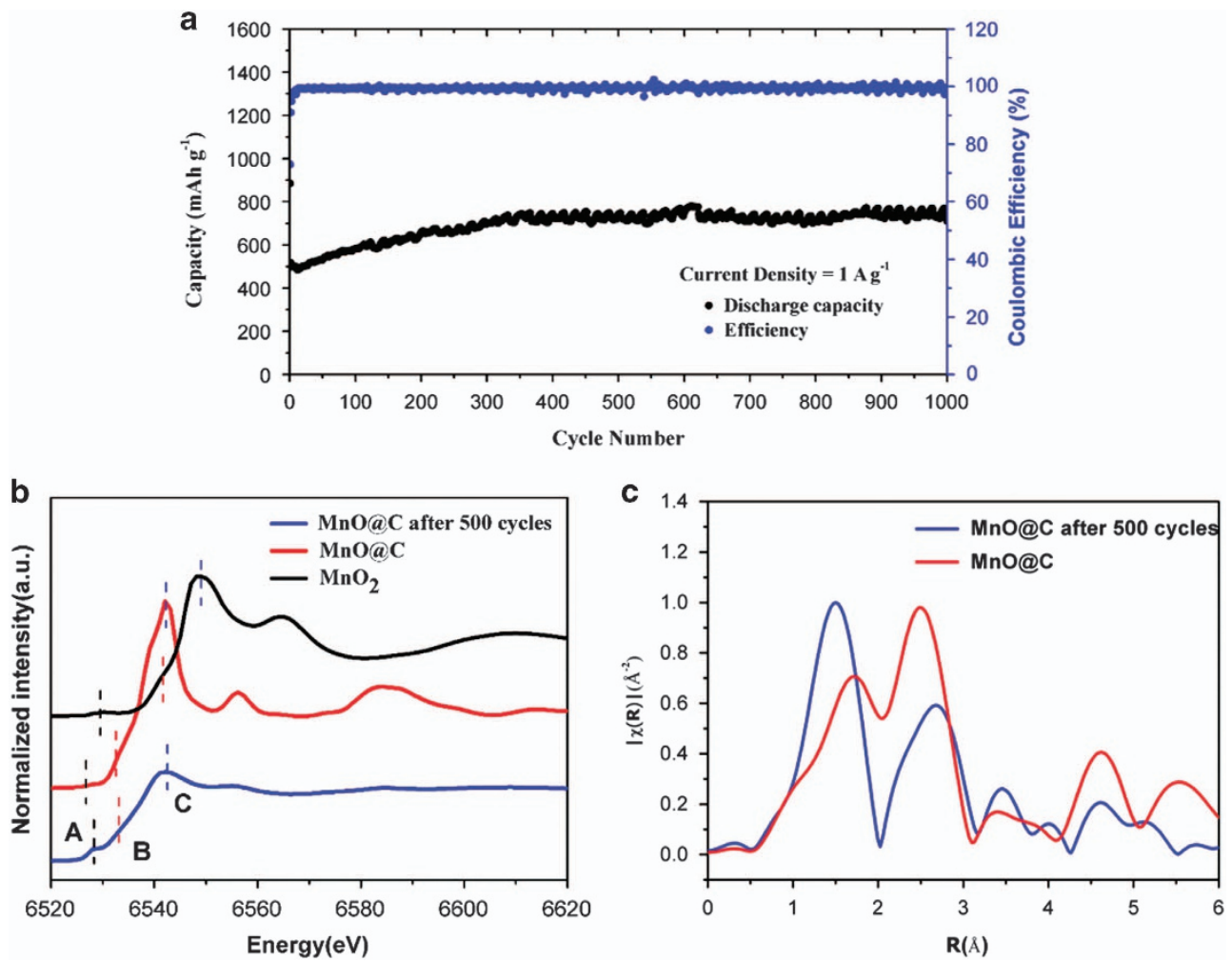

Figure 8 (a) Cycling performance and Coulombic efficiency of MnO@C electrodes at $1 \mathrm{Ag}^{-1}$ current density. (b) Ex situ Mn K-edge X-ray absorption spectroscopy spectra and (c) radial-structure functions for $\mathrm{MnO} @ \mathrm{C}$ electrode after 500 cycles and for standard samples of $\mathrm{MnO}_{0} \mathrm{C}$ and $\mathrm{MnO}_{2}$.

at current rates of $1,2,3,4$ and $5 \mathrm{Ag}^{-1}$, respectively, indicating a truly outstanding rate performance. The apparent diffusion coefficient was determined by a Randles-Sevcik analysis ${ }^{30,31}$ of cyclic voltammogram measurements at different scan rates to be $3.21 \times 10^{-8} \mathrm{~cm}^{2} \mathrm{~s}^{-1}$ for the MnO@C during the discharge process (Supplementary Figure S8). The high apparent diffusion coefficient at room temperature explains the absence of substantial diffusional polarization, even at $5 \mathrm{Ag}^{-1}$. After charge-discharge at a high rate $\left(30 \mathrm{~A} \mathrm{~g}^{-1}\right)$, the capacity can still reach its initial value $\left(957.8 \mathrm{~mA} \mathrm{~h}^{-1}\right)$ at $0.2 \mathrm{Ag}^{-1}$, implying an excellent capacity retention. To the best of our knowledge, this highrate behavior is unprecedented among other reports on $\mathrm{MnO}$. For this comparison, we selected the very best reports in the literature. ${ }^{10-18,22}$ Considering the ultrafine diameter of $\mathrm{MnO}$ and the flexible nature of amorphous carbon with its protective effect as a matrix, this indicates that such an outstanding nanostructure can indeed relieve the strain and stress caused by volume variation in $\mathrm{MnO}$ nanowires. Moreover, we also synthesized the $\mathrm{MnO} @ \mathrm{C}$ nanocomposite containing 6\% amorphous carbon by reducing the amount of phthalocyanine from $1 \mathrm{mmol}$ to $0.75 \mathrm{mmol}$, as shown in Supplementary Figure S9a. All the diffraction peaks shown in Supplementary Figure S9b could be assigned to a pure cubic phase of MnO (JCPDS no. 07-0230). However, calculated by the Scherrer equation, the average diameter of the $\mathrm{MnO}$ is larger than that of $\mathrm{MnO} @ \mathrm{C}$ nanomaterials containing $25.1 \%$ amorphous carbon. The SEM and TEM images (Supplementary Figures $59 \mathrm{c}$ and d) also demonstrate an irregular particle morphology. This may be because less carbon cannot prevent the aggregation of $\mathrm{MnO}$ nanowires in the pyrolysis process. The obtained MnO@C nanocomposite containing6\% amorphous carbon can deliver $635.5 \mathrm{~mA} \mathrm{~h} \mathrm{~g}^{-1}$ at a current density of $0.2 \mathrm{~A} \mathrm{~g}^{-1}$ after 50 cycles, and $246 \mathrm{~mA} \mathrm{~h} \mathrm{~g}^{-1}$ at a current density of $1 \mathrm{Ag}^{-1}$ after 200 cycles, as shown in Supplementary Figures S9e and f. In comparison with the nanowires $\mathrm{MnO} @ \mathrm{C}$ composite containing 25.1\% carbon, the decrease of capacity of the $\mathrm{MnO} @ \mathrm{C}$ nanocomposite containing 6\% amorphous carbon, especially for the rate capacity, is mainly related to the increase of irregular $\mathrm{MnO}$ particle size.

The excellent high-rate performance and stability of the MnO@C nanowires are attributed to the unique interconnected nanostructure, resulting from a high contact area between the electrolyte and electrode, as well as a bridge for electron transfer between carbon matrixes, leading to enhanced electrical conductivity. When the current density is increased to $1 \mathrm{Ag}^{-1}$, the initial reversible capacity of the composite is $\sim 500.2 \mathrm{~mA} \mathrm{~h} \mathrm{~g}^{-1}$ and then grows slowly with repeated cycles, until the $\sim 300$ th cycle. Subsequently, the specific capacity of the composite stabilizes gradually and reaches $757.4 \mathrm{~mA} \mathrm{~h} \mathrm{~g}^{-1}$ (about $100 \mathrm{mAh} \mathrm{cm}^{-3}$ ) after 1000 discharge/charge cycles (Figure 8a). This phenomenon of the gradual increase is also commonly observed in other TMO anodes and can largely be ascribed to the formation of high-oxidation state products or the redistribution of $\mathrm{MnO}$ material. ${ }^{15,32-34}$ In the present work, we measured the ex situ Mn K-edge XAS spectrum for the MnO@C electrode after 500 cycles (Figure $8 \mathrm{~b}$ ). The spectrum of the sample presents three significant features: the pre-edge peak A, peak B and main peak C. Peak A represents the $1 \mathrm{~s}$ to $3 \mathrm{~d}$ transition, which is normally forbidden and can only be allowed due to the hybridization of the $\mathrm{p}$ and $\mathrm{d}$ orbits. Peak B can be asigned to the continuum threshold of core transitions to dipole-allowed $\mathrm{p}$-like states of $\mathrm{t} 1$ symmetry. The main absorption edge features, peak $\mathrm{C}$, were attributed to the purely dipole-allowed $1 \mathrm{~s}$ to $4 \mathrm{p}$ transition. Using the 'fingerprint' of the Mn K-edge XAS, we can easily exclude the possibility of $\mathrm{MnO}_{2} \cdot{ }^{35,36} \mathrm{~A}$ small positive shift of the absorption edge compared with pristine $\mathrm{MnO} @ \mathrm{C}$ could be related to the pulverization of the $\mathrm{MnO}$ during the charge/discharge process. ${ }^{37}$ The radial-structure functions of the $\mathrm{Mn} \mathrm{K}$-edge (Figure 8c) 
demonstrate the obvious increase in the peak height at 1.5 angstroms, implying an increase in the ordering of the $\mathrm{O}^{2-}$ ions in the $\mathrm{MnO}$ structure, which induces the fast diffusion of Li ions and a low internal resistance. ${ }^{38}$ As for the change in the radial distribution function of the second shell of the MnO@C nanowire, it may be consistent with the increase in the disorder degree of the $\mathrm{Mn}-\mathrm{Mn}$ shell corresponding to the coordination of the second shell, which was supported by the increases of Debye-Waller factor of Mn-Mn.

An electrochemical impedance spectroscopy analysis was performed to further investigate the charge-transfer resistance of the pure $\mathrm{MnO}$ nanoparticle and MnO@C nanowires electrode. This revealed that the $\mathrm{MnO@C} \mathrm{nanowires} \mathrm{electrode} \mathrm{yields} \mathrm{a} \mathrm{far} \mathrm{lower} \mathrm{resistance} \mathrm{than} \mathrm{the}$ pure $\mathrm{MnO}$ nanoparticle (Supplementary Figure S10a). These differences not only confirm the rational structure but also demonstrate the improved Li-reaction kinetics of the $\mathrm{MnO} @ \mathrm{C}$ nanowires composite. ${ }^{39}$ We also found that the charge-transfer resistance decreases with repeated cycles (Supplementary Figure S10b), which is ascribed to the $\mathrm{MnO} @ \mathrm{C}$ nanowires composite structure and its activation process. ${ }^{40}$ Such unique results indicate better contact between the active material and electrolyte, improved conversion reaction kinetics and a higher reaction area of the $\mathrm{MnO} @ \mathrm{C}$ nanowires composite. Thus, it is reasonable that the $\mathrm{MnO} @ \mathrm{C}$ nanowires composite exhibited a relatively higher capacity and an excellent rate capability.

In summary, $\mathrm{MnCO}_{3}$ nanowires were synthesized by an epitaxial growth mechanism under simple hydrothermal conditions. The $\mathrm{Mn} / \mathrm{Si}$ molar ratio is the key parameter in the nanowire fabrication. $\mathrm{MnO}$ nanowires approximately $5-10 \mathrm{~nm}$ in diameter were obtained through a facile polymerization-pyrolysis process. The rationally designed MnO@C nanocomposite exhibited excellent charge transfer kinetics and an extremely high electrochemical performance compared with graphite, including stable specific capacities of $285.9 \mathrm{~mA} \mathrm{~h} \mathrm{~g}^{-1}$ at $30 \mathrm{Ag}^{-1}$ and $757.4 \mathrm{~mA} \mathrm{~h} \mathrm{~g}^{-1}$ at $1 \mathrm{Ag}^{-1}$ after 1000 cycles. Moreover, considering its simplicity and the new nanowire growth mechanism, this strategy may inspire studies of other TMO nanomaterials with special orientation to improve their physical chemistry properties.

\section{CONFLICT OF INTEREST}

The authors declare no conflict of interest.

\section{ACKNOWLEDGEMENTS}

This work was financially supported by the National Nature Science Foundation of China (No. 11179001) and the National Basic Research Program of China (2012CB825800). We would also like to acknowledge the staff of the XAS beamlines of the Beijing Synchrotron Radiation Facility.

Author contributions: HW and DX designed this study. HW prepared materials and carried out the electrochemical experiments. HW, JM and BL carried out of the XRD investigation. HW, LA and JK carried out of the TEM investigation. HW carried out data processing and prepared figures. HW and DX wrote the manuscript. PY suggested the proposed mechanism and all of the authors contributed to the scientific discussion.

1 Zhang, Q., Uchaker, E., Candelaria, S. L. \& Cao, G. Nanomaterials for energy conversion and storage. Chem. Soc. Rev. 42, 3127-3171 (2013).

2 Kang, B. \& Ceder, G. Battery materials for ultrafast charging and discharging. Nature 458, 190-193 (2009).

3 Devan, R. S., Patil, R. A., Lin, J. H., Cao, G. \& Ma, Y. R. One-dimensional metal-oxide nanostructures: recent developments in synthesis, characterization, and applications. Adv. Funct. Mater. 22, 3326-3370 (2012).

4 Xu, X., Luo, Y. Z., Mai, L. Q., Zhao, Y. L., An, Q. Y., Xu, L., Hu, F., Zhang, L. \& Zhang, Q. J. Topotactically synthesized ultralong $\mathrm{LiV}_{3} \mathrm{O}_{8}$ nanowire cathode materials for high-rate and long-life rechargeable lithium batteries. NPG Asia Mater. 4, e20 (2012).
5 Gaikwad, A. M., Zamarayeva, A. M., Rousseau, J., Chu, H., Derin, I. \& Steingart, D. A. Highly stretchable alkaline batteries based on an embedded conductive fabric. Adv. Mater. 24, 5071-5076 (2012).

6 Tamaekong, N., Liewhiran, C., Wisitsoraat, A., Tuantranont, A. \& Phanichphant, S. $\mathrm{NO}_{2}$ sensing properties of flame-made $\mathrm{MnO}_{\mathrm{x}}$-loaded $\mathrm{ZnO}$-nanoparticle thick film. Sens. Actuators B 204, 239-249 (2014).

7 Dong, A., Chen, J., Ye, X., Kikkawa, J. M. \& Murray, C. B. Enhanced thermal stability and magnetic properties in $\mathrm{NaCl}$-type FePt-MnO binary nanocrystal superlattices. J. Am. Chem. Soc. 34, 13296-13299 (2011).

8 Schladt, T. D., Koll, K., Prüfer, S., Bauer, H., Natalio, F., Dumele, O., Raidoo, R., Weber, S., Wolfrum, U., Schreiber, L. M., Radsak, M. P., Schild, H. \& Tremei, W. Multifunctional superparamagnetic $\mathrm{MnO} \mathrm{SiO}_{2}$ core/shell nanoparticles and their application for optical and magnetic resonance imaging. J. Mater. Chem. 22, 9253-9262 (2012).

9 Gu, T., Jin, R., Liu, Y., Liu, H., Weng, X. \& Wu, Z. Promoting effect of calcium doping on the performances of $\mathrm{MnO}_{\mathrm{x}} / \mathrm{TiO}_{2}$ catalysts for $\mathrm{NO}$ reduction with $\mathrm{NH}_{3}$ at low temperature. Appl. Catal. B 129, 30-38 (2013).

10 Xia, Y., Xiao, Z., Dou, X., Huang, H., Lu, X., Yan, R., Gan, Y., Zhu, W., Tu, J., Zhang, W. \& Tao, X. Green and facile fabrication of hollow porous $\mathrm{MnO} / \mathrm{C}$ microspheres from microalgaes for lithium-ion batteries. ACS Nano 7, 7083-7092 (2013).

11 Jiang, H., Hu, Y., Guo, S., Yan, C., Lee, P. S. \& Li, C. Rational design of MnO/carbon nanopeapods with internal void space for high-rate and long-life li-ion batteries. ACS Nano 8, 6038-6046 (2014).

12 Chen, W. M., Qie, L., Shen, Y., Sun, Y. M., Yuan, L. X., Hu, X. L., Zhang, W. X. \& Huang, $Y$. H. Superior lithium storage performance in nanoscaled $\mathrm{MnO}$ promoted by N-doped carbon webs. Nano Energy 2, 412-418 (2013).

$13 \mathrm{Liu}$, Y., Zhao, X., Li, F. \& Xia, D. Facile synthesis of $\mathrm{MnO} / \mathrm{C}$ anode materials for lithium-ion batteries. Electrochim. Acta 56, 6448-6452 (2011).

14 Fang, X., Lu, X., Guo, X., Mao, Y., Hu, Y. S., Wang, J., Wang, Z., Wu, F., Liu, H. $\&$ Chen, L. Electrode reactions of manganese oxides for secondary lithium batteries. Electrochem. Commun. 12, 1520-1523 (2010).

15 Zhang, S., Zhu, L., Song, H., Chen, X. \& Zhou, J. Enhanced electrochemical performance of $\mathrm{MnO}$ nanowire/graphene composite during cycling as the anode material for lithium-ion batteries. Nano Energy 2, 172-180 (2014).

16 Li, X., Xiong, S., Li, J., Liang, X., Wang, J., Bai, J. \& Qian, Y. MnO@carbon core-shell nanowires as stable high-performance anodes for lithium-ion batteries. Chem. - Eur. J 19, 11310-11319 (2013)

17 Ding, Y. L., Wu, C. Y., Yu, H. M., Xie, J., Cao, G. S., Zhu, T. J., Zhao, X. B. \& Zeng, Y. W. Coaxial $\mathrm{MnO} / \mathrm{C}$ nanotubes as anodes for lithium-ion batteries. Electrochim. Acta 56, 5844-5848 (2011).

18 Cai, Z., Lin, X., Yan, M., Han, C., He, L., Hercule, K. M., Niu, C., Yuan, Z., Xu, W., Qu, L., Zhao, K. \& Mai, L. Manganese oxide/carbon yolk-shell nanorod anodes for high capacity lithium batteries. Nano Lett. 15, 738-744 (2015).

19 Wang, X. \& Li, Y. Hydrothermal reduction route to $\mathrm{Mn}(\mathrm{OH})_{2}$ and $\mathrm{MnCO}_{3}$ nanocrystals. Mater. Chem. Phys. 82, 419-422 (2003).

20 Wang, C., Yin, L., Xiang, D. \& Qi, Y. Uniform carbon layer coated $\mathrm{Mn}_{3} \mathrm{O}_{4}$ nanorod anodes with improved reversible capacity and cyclic stability for lithium Ion batteries. ACS Appl. Mater. Interf 4, 1636-1642 (2012).

21 Moore, P. B. \& Araki, T. Braunite: its structure and relationschip to Bixbyite, and some insights on the genealogy of fluorite derivative structures. Am. Mineral. 61, 1226-1240 (1976).

$22 \mathrm{Gu}, \mathrm{X}$., Chen, L., Ju, Z., Xu, H., Yang, J. \& Qian, Y. Controlled growth of porous $\alpha-\mathrm{Fe}_{2} \mathrm{O}_{3}$ branches on $\beta-\mathrm{MnO}_{2}$ nanorods for excellent performance in lithium-ion batteries. Adv. Funct. Mater. 23, 4049-4056 (2013).

23 Zhou, W., Cheng, C., Liu, J., Tay, Y. Y., Jiang, J., Jia, X., Zhang, J., Gong, H., $\mathrm{Hng}, \mathrm{H}$. H., Yu, T. \& Fan, H. J. Epitaxial growth of branched $\alpha-\mathrm{Fe}_{2} \mathrm{O}_{3} / \mathrm{SnO}_{2}$ nano-heterostructures with improved lithium-ion battery performance. Adv. Funct. Mater. 21, 2439-2445 (2011).

24 Bai, L., Ma, X., Liu, J., Sun, X., Zhao, D. \& Evans, D. G. Rapid separation and purification of nanoparticles in organic density gradients. J. Am. Chem. Soc. 132, 2333-2337 (2010)

25 Luo, W., Hu, X., Sun, Y. \& Huang, Y. Controlled synthesis of mesoporous MnO/C networks by microwave irradiation and their enhanced lithium-storage properties. Appl. Mater. Interf. 5, 1997-2003 (2013).

26 Zhao, X., Xia, D., Gu, L., Yue, J., Li, B., Wei, H., Yan, H., Zou, R., Wang, Y., Wang, X., Zhang, Z. \& Li, J. High-performance self-organized Si nanocomposite anode for lithium-ion batteries. J. Energy Chem 23, 291-300 (2014).

27 Xiao, Y., Wang, X., Wang, W., Zhao, D. \& Cao, M. Engineering hybrid between MnO and $\mathrm{N}$-doped carbon to achieve exceptionally high capacity for lithium-ion battery anode. ACS Appl. Mater. Interf. 6, 2051-2058 (2014).

28 Zhao, X., Xia, D. \& Yue, J. S. Liu, In-situ generated nano-Fe3C embedded into nitrogendoped carbon for high performance anode in lithium ion battery. Electrochim. Acta 116, 292-299 (2014).

29 Yue, J., Zhao, X. \& Xia, D. Electrochemical lithium storage of C/Co composite as an anode material for lithium ion batteries. Electrochem. Commun. 18, 44-47 (2012).

30 Wang, B., Li, S., Liu, J., Yu, M., Li, B. \& Wu, X. An efficient route to a hierarchical $\mathrm{CoFe}_{2} \mathrm{O}_{4} @ g$ graphene hybrid films with superior cycling stability and rate capability for lithium storage. Electrochim. Acta 146, 679-689 (2014).

31 Wang, X., Xiang, Q., Liu, B., Wang, L., Luo, T., Chen, D. \& Shen, G. TiO 2 modified FeS nanostructures with enhanced electrochemical performance for lithium-ion batteries. Sci. Rep. 3, 2007-2015 (2013). 
32 Sun, Y., Hu, X., Luo, W., Xia, F. \& Huang, Y. Reconstruction of conformal nanoscale $\mathrm{MnO}$ on graphene as a high-capacity and long-life anode material for lithium ion batteries. Adv. Funct. Mater. 23, 2436-2444 (2013).

33 Wang, S., Xing, Y., Xu, H. \& Zhang, S. MnO nanoparticles interdispersed in 3D porous carbon framework for high performance lithium-ion batteries. ACS Appl. Mater. Interfaces 6, 12713-12718 (2014).

34 Xu, G. L., Xu, Y. F., Fang, J. C., Fu, F., Sun, H., Huang, L., Yang, S. \& Sun, S. G. Facile synthesis of hierarchical micro/nanostructured $\mathrm{MnO}$ material and its excellent lithium storage property and high performance as anode in a $\mathrm{MnO} / \mathrm{LiNi}_{0.5} \mathrm{Mn}_{1.5} \mathrm{O}_{4}-\delta$ lithium ion battery. ACS Appl. Mater. Interf. 5, 6316-6323 (2013).

35 Zhong, K., Zhang, B., Luo, S., Wen, W., Li, H., Wang, Z. X. \& Chen, L. MnO powder as anode active materials for lithium ion batteries. J. Power Sources 196, 6802-6808 (2011).

36 Beill, M., Scafati, A., Bianconi, A., Mobilio, S., Palladino, L., Reale, A. \& Burattini, E. $\mathrm{X}$-ray absorption near edge structures (XANES) in simple and complex $\mathrm{Mn}$ compounds. Solid State Commun. 35, 355-361 (1980).

37 Richter, B., Kuhlenbeck, H., Freund, H. J. \& Bagus, P. S. Cluster core-level bindingenergy shifts: the role of lattice strain. Phys. Rev. Lett. 93, 026805-026809 (2004).

$38 \mathrm{Ha}$, D. H., Moreau, L. M., Honrao, S., Hennig, R. G. \& Robinson, R. D. The oxidation of cobalt nanoparticles into Kirkendall-hollowed $\mathrm{CoO}$ and $\mathrm{Co}_{3} \mathrm{O}_{4}$ : The diffusion mechanisms and atomic structural transformation. J. Phys. Chem. C 117, 14303-14312 (2013).

39 Xiong, P., Liu, B., Teran, V., Zhao, Y., Peng, L., Wang, X. \& Yu, G. Chemically integrated two-dimensional hybrid zinc manganate/graphene nanosheets with enhanced lithium storage capability. ACS Nano 8, 8610-8616 (2014).

40 Zhong, Y., Yang, M., Zhou, X., Luo, Y., Wei, J. \& Zhou, Z. Orderly packed anodes for high-power lithium-ion batteries with super-long cycle life: rational design of $\mathrm{MnCO}_{3}$ / large-area graphene composites. Adv. Mater. 27, 806-812 (2014).

\section{(c) (i)}

This work is licensed under a Creative Commons Attribution 4.0 International License. The images or other third party material in this article are included in the article's Creative Commons license, unless indicated otherwise in the credit line; if the material is not included under the Creative Commons license, users will need to obtain permission from the license holder to reproduce the material. To view a copy of this license, visit http:// creativecommons.org/licenses/by/4.0/

Supplementary Information accompanies the paper on the NPG Asia Materials website (http://www.nature.com/am) 